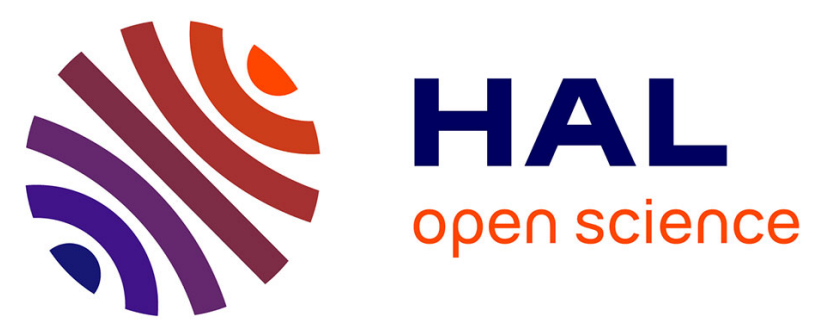

\title{
Liver transplantation for iatrogenic bile duct injury during cholecystectomy: a French retrospective multicenter study
}

Laurence Chiche, Maxime Guieu, Philippe Bachellier, Bertrand Suc, Olivier Soubrane, Karim Boudjema, Francis Navarro, René Adam, Jean-Christophe Vaillant, Ephrem Salame, et al.

\section{To cite this version:}

Laurence Chiche, Maxime Guieu, Philippe Bachellier, Bertrand Suc, Olivier Soubrane, et al.. Liver transplantation for iatrogenic bile duct injury during cholecystectomy: a French retrospective multicenter study. HPB, 2021, 10.1016/j.hpb.2021.08.817 . hal-03336864

\section{HAL Id: hal-03336864 https://hal.science/hal-03336864}

Submitted on 20 Sep 2021

HAL is a multi-disciplinary open access archive for the deposit and dissemination of scientific research documents, whether they are published or not. The documents may come from teaching and research institutions in France or abroad, or from public or private research centers.
L'archive ouverte pluridisciplinaire HAL, est destinée au dépôt et à la diffusion de documents scientifiques de niveau recherche, publiés ou non, émanant des établissements d'enseignement et de recherche français ou étrangers, des laboratoires publics ou privés. 


\section{LIVER TRANSPLANTATION FOR IATROGENIC BILE DUCT INJURY DURING CHOLECYSTECTOMY: A FRENCH RETROSPECTIVE MULTICENTER STUDY}

Laurence Chiche MD, Facs(Hon) ${ }^{1}$, Maxime Guieu MD ${ }^{1}$, Philippe Bachellier $\mathrm{PhD}^{2}$, Bertrand Suc $\mathrm{PhD}^{3}$,

Olivier Soubrane $\mathrm{PhD}^{4}$, Karim Boudjema $\mathrm{MD} \mathrm{PhD}^{1}$, Francis Navarro $\mathrm{PhD}^{2}$, René Adam $\mathrm{PhD}^{3}$, Jean-Christophe Vaillant $\mathrm{PhD}^{4}$, Ephrem Salame $\mathrm{PhD}^{5}$, Bruno Heyd $\mathrm{PhD}^{10}$, Stéphanie Truant $\mathrm{PhD}^{11}$, Jean-Philippe Adam $\mathrm{MD}^{1}$, Christophe Laurent $\mathrm{PhD}^{1}$

${ }^{1}$ Department of Digestive Surgery, Bordeaux University Hospital, Pessac, France

${ }^{2}$ Department of Digestive Surgery, University Hospital of Strasbourg, France

${ }^{3}$ Department of Visceral Surgery, Toulouse-Rangueil University Hospital, Toulouse, France

${ }^{4}$ Department of Hepatobiliopancreatic Surgery and Liver Transplantation, AP-HP, Beaujon Hospital, Clichy, France

${ }^{1}$ Department of Hepatobiliary and Digestive Surgery, Pontchaillou Hospital, University Hospital Rennes 1, Rennes 35033 France

${ }^{2}$ Department of Visceral Surgery, University Hospital of Montpellier, France

${ }^{3}$ Hepato-Biliary Center, AP-HP Paul Brousse Hospital, University of Paris-Sud, Villejuif, France.

${ }^{4}$ Department of Hepatobiliopancreatic Surgery and Liver Transplantation, AP-HP, PitieSalpetriere, Paris, France

${ }^{5}$ Department of Digestive Surgery, Hepatobiliary Surgery and Liver Transplantation,

University Hospital of Tours, Tours, France 
${ }^{10}$ Department of Digestive Surgery, Universtity Hospital of Besançon, Besançon, France

${ }^{11}$ Department of Digestive Surgery and Transplantation, Lille University Medical Center,

Lille, France

Funding

We declare we received no funding for this manuscript.

\section{Disclosure}

Declarations of interest : none.

\section{Corresponding author}

Pr. Laurence CHICHE

Department of Digestive and endocrine Surgery

Haut-Leveque Hospital, Bordeaux University Hospital

Avenue Magellan

33600 Pessac, FRANCE e-mail:

laurence.chiche@chu-bordeaux.fr

Fax: +33557656027

\section{Additional title page information}

Original article.

The results of this study were presented on June 3th 2019, during the 13th Congress of the E-AHPBA in Amsterdam. Any further publication of the data (e.g. in secondary analysis or translation) will not constitute redundant publication, will not breach copyright, and will reference the original publication.

\section{Abbreviations}

CHA: Common Hepatic Artery

CMV: Cytomegalovirus 
ERCP: Endoscopic Retrograde Cholangiopancreatography

BDI: Bile Duct Injury

MELD: Model for End-Stage Liver Disease

LT: Liver Transplantation

PV: Portal Vein

RHA: Right Hepatic Artery

TIPS: Transjugular Intrahepatic Portosystemic Shunt

\section{Abstract}

BACKGROUND : Major bile duct injuries (BDI) following cholecystectomy requires complex reconstructive surgery. The aim was to collect the liver transplantations (LT) performed in France for major BDI following cholecystectomy, to analyze the risk factors and to report the results.

METHODS : National multicenter observational retrospective study. All the patients who underwent a LT in France between 1994 and 2017 , for BDI following cholecystectomy, were included.

RESULTS : 30 patients were included. 25 BDI occurred in non hepato-biliary expert centers, 20 were initially treated in these centers. Median time between injury and LT was 3 years in case of an associated vascular injury (11 injuries), versus 11.7 years without vascular injury ( $\mathrm{p}=0.006$ ). Post-transplant morbidity rate was $86.7 \%$, mortality $23.5 \%$ at 5 years. DISCUSSION : Iatrogenic BDI remains a real concern with severe cases, associated with vascular damages or leading to cirrhosis, with no solution but LT. It is associated with high morbidity and not optimal results. This enlights the necessity of early referral of all major BDI in expert centers to prevent dramatic outcome. Decision to perform transplantation should be taken before dismal infectious situations or biliary cirrhosis and access to graft should be facilitated by Organ Sharing Organizations 


\section{INTRODUCTION}

Cholecystectomy is a common surgical procedure, with 116000 procedures carried out in France in 2017 (1). Iatrogenic bile duct injury (BDI) is a rare, but serious complication of cholecystectomy. Iatrogenic BDI is defined as accidental damage to the biliary tree during surgery, and may be identified during or after the procedure based on biliary leak or obstruction, including cystic stump leaks. The presence and localization of associated vascular injury is important to identify(2,3), although its prognostic significance is debated in the literature(4-6). While most BDI cases are treated without sequelae, major BDI generally requires complex reconstructive surgery, including repair and reconstruction of the biliary system, hepatectomy or, in rare cases, liver transplantation (LT).

The aim of our study was to review the LT performed in France for major iatrogenic BDI following cholecystectomy, the risk factors for adverse outcomes, and to make recommendations for the management of these patients.

\section{METHODS}

We conducted a national multicenter observational retrospective study, across all French centers performing, between 1994 and 2017. All patients treated for iatrogenic BDI following cholecystectomy were eligible for participation. 
The study summary was sent to each French LT center prior to commencing the project. For each participating center, unique corresponding number was created. This enabled the secure transfer of relevant patient data, including hospital reports, operative and histopathological reports, relevant imaging and other appropriate documents. Data handling and analysis was carried out centrally, at the coordinating center, by a dedicated study coordinator.

Data were collected on gender, age at cholecystectomy, age at LT, indication of cholecystectomy, surgical approach, expert or nonexpert center (for cholecystectomy and BDI management with an expert center being defined as a high-volume center familiar with reconstructive hepatobiliary surgery), diagnosis of BDI, delay of BDI diagnosis, type of BDI using Strasberg(7) classification, presence of associated vascular injury, average time between BDI and first treatment, number of surgeries per patient between BDI and LT, usage of endoscopy, usage of interventional radiology, median time between BDI and enrolment onto the LT waiting list, waiting time before LT, median time between BDI and LT, median MELD score, involvement of an expert component, indication of LT, re-transplantation, morbidity post-LT, early graft loss, and overall graft and patient survival.

Expert component is a derogation delivered by French Organ Sharing Organization, to allow a patient to have a LT with a low MELD score. Those patients, to access grafts, need a special prioritization as MELD score exceptions, since their MELD is low and do not reflect the severity of the situation. In France, an "expert component" has to be delivered by the French Organ Sharing Organization after evaluation by two independent transplant experts.

Study end points were perioperative 30-day mortality and graft and patient survival.

All data related to LT is registered, a priori, in the National French transplant database, therefore individual institutional ethic approval is not required. 


\section{Statistical analysis}

Data collection and statistical analysis were performed using XLSTAT software (Addinsoft) and Microsoft Office Excel 2013 software. Data were expressed as absolute values and percentages for ordinal variables; median and/or mean and extreme values were reported for continuous variables.

Univariate analyses were performed using Student's t-test, as appropriate, for comparing quantitative variables (in particular delays) between groups for normally distributed data. Analysis of variance (ANOVA) was used to compare quantitative variables among multiple groups. Survival after transplantation was calculated using the Kaplan-Meier method and the log-rank test was used to analyze differences in survival.

\section{RESULTS}

Thirty patients underwent LT between 01/01/1994 and 12/31/2017 for iatrogenic BDI (Table

1) across 11 expert French LT centers. This represents $0.13 \%$ of the total workload of LTs

(23 329) performed over the duration of the study. Twenty-three of BDIs (76.7\%) occurred after 1990, with 21 LTs (70\%) carried out between 2006 and 2017. The trend in LT for BDI relative to total LT in this period is presented in Figure 1.

Nineteen patients were females (63.3\%), and the median age at cholecystectomy was 40 [range 9-66]. The median age at LT was 52 [range 22-68]. Pre-existing hepatic disease was absent in all patient at the time of index BDI. The indications for cholecystectomy were symptomatic gallbladder stones in ten cases (33.3\%), acute cholecystitis in nine cases (30\%), common bile duct lithiasis in one case (3.3\%), biliary pancreatitis in two cases (6.7\%), and unknown in eight cases (26.7\%). In twenty (66.7\%) patients the BDI occurred during a laparoscopic cholecystectomy.

Presentation of iatrogenic BDI included; biliary sepsis (seven cases), bile leak (seven cases), cholestatic jaundice (five cases), upper gastrointestinal bleeding (one case), or secondary biliary cirrhosis (one case) (Table 2). The exact clinical presentation was unknown 
in nine patients (30\%). The median time to diagnosis of BDI was 15 days post cholecystectomy, with four cases diagnosed during surgery, thirteen in the first 15 postoperative days, and nine after 15 days post-cholecystectomy. Time of diagnosis was unknown for the remaining four patients. The period before diagnosis was not recorded in the medical files for four of patients. According to Strasberg classification, the types of BDI included B (one case), C (one case), D (six cases), E1 (three cases), E2 (six cases), E3 (three cases), E4 (five cases), and non-classifiable (five cases). Eleven patients (36.6\%) had an associated vascular injury : 10 injuries of the right hepatic artery, including one associated with a portal vein injury, 1 injury of the common hepatic artery.

Twenty-five cases of BDI (83.4\%) occurred in non-expert centers, and 20 of them $(80 \%)$ were initially treated in these centers. The average time between BDI and treatment was 24 months (range 0,23-108) (Table 3). The average number of surgeries per patient before $\mathrm{LT}$ was $2.5 \pm 1.13$. Thirteen $(43.3 \%)$ patients required endoscopy/ERCP, and a biliary stent was used in 4 cases (30.8\%). Fourteen $(46.7 \%)$ patients required interventional radiology, with a biliary drain performed in eleven patients $(78.6 \%)$, and a Transjugular Intrahepatic Portosystemic Shunt (TIPS) performed in three patients $(21.4 \%)$. Eleven hepatico-jejunal anastomoses were initially performed; nine of them $(81.8 \%)$ were complicated by stenosis.

The median time interval between BDI and enrolment onto the LT waiting list was 8.5 years (range 0.2-32) (Table 4). The median waiting list duration was 3 months (range 0.1-116). The median time between BDI and LT was 10 years (range 0.2-32). Median MELDscore at LT was 16 (range 6-40). Eight patients (26.7\%) required an expert component to access LT, with a median MELD-score of 8; the median time between expert component and LT was 2 months (range 0.1-6.5). Three LTs were performed as emergencies (in less than 7 days after list inscription).

The median time between BDI and LT was 3 years (range 0.2-18) with associated vascular lesion, versus 11.7 years (range 6-32) without vascular lesion ( $\mathrm{p}=0.006$ ). It was 42.5 
months (range 9-136) if BDI occurred in an expert center, versus 144 months (range 2-384) in a non-expert center ( $\mathrm{p}=0.03$ ).

The indications for LT included chronic liver failure (fourteen patients), uncontrolled biliary sepsis (six patients), uncontrolled portal hypertension (five patients), biliovascular destruction (three patients), acute liver failure (one patient), and refractory pruritus (one patient).

The median follow-up period was 6.1 years (range 0-16) after LT. Morbidity was 86.7\% (Table 5), including severe complications in $80 \%$ of cases (Clavien-Dindo $\geq$ III). Two patients $(6.7 \%)$ required re-transplantation for extended biliary necrosis (1 patient) and secondary biliary cirrhosis (1 patient). Graft survival was $76 \%$ at 3 months, $73 \%$ at 1 year, and $69 \%$ at 5 years (Table 6). Patient survival was $80 \%$ at 3 months, and $76.5 \%$ at 1 year and 5 years. The survival curves for grafts and patients are shown in Figure 2.

Mortality post-LT was $23.5 \%$ (seven patients). The causes of death included hemorrhagic shock (three patients), septic shock (one patient), mesenteric ischemia (one patient), and unknown for the remaining two patients.

\section{DISCUSSION}

We present a comprehensive review of liver transplantations for BDI following cholecystectomy in France. There are a number of case studies that have been reported in the current literature documenting outcomes in this cohort of patients $(8,3,9-12)$, with a small number of multicenter studies available (Spain : 25 cases (13), Argentina : 18 cases (14), United States : 61 LT (15)). Indeed, BDI accounts for a very small percentage of workload for liver transplantation, however, it remains a major concern in the field of hepatobiliary surgery. Iatrogenic BDI is a relatively rare, but serious complication of cholecystectomy, often occurring in young patients initially operated on for a benign disease(16), with potentially life changing consequences (17). The incidence of BDI in laparoscopic cholecystecotmy has plateaued to $0.6 \%$ since its inception (18), however, the severity of BDI associated with 
laparoscopic surgery is greater than that associated with open cholecystectomy (8). This is most likely to be due to the underlying mechanism of the injury, the associated vascular injuries $(6,19)$ and, sometimes, the requirement for multiple surgical procedures to repair the injury.

In our series, twenty BDI were identified following laparoscopic cholecystectomy, with associated vascular injuries in eleven cases. The incidence of LT for BDI in France is increasing, compared to other parts of the world (13). However, this is not associated with a concurrent rise in the rate of BDI, and is likely to reflect the increase in the inappropriate management of BDI(22). Similar to published evidence, our study supports the observation that LT in iatrogenic BDI is reserved for patients presenting with late complications of secondary biliary cirrhosis, including sepsis, jaundice, portal hypertension or refractory pruritus.The time interval between BDI and the LT is very long (3 years in the case of vascular lesions and 11.7 years without), which reflects its indication being reserved for long-term sequalae of BDI. Furthermore, LT is considered to be a final resort, following multiple procedures (surgery, endoscopy $+/$ - interventional radiology (23). In severe BDI (Strasberg E in $56 \%$ of the cases), it is likely that the indication for LT was due to inappropriate repair carried out under poor conditions and/or by non-experts centers in $87 \%$ of cases (22). It is therefore essential that all BDI cases (> or = Strasberg B) are managed appropriately in expert hepatobiliary centers. In the current era, in which surgeons are often more experienced with laparoscopy than open surgery, it may be preferable to refer bile duct injury patients to an appropriate institution than to convert them to open surgery or re-operate.

With respect to the outcomes of LT for BDI, we confirmed the results of previous studies showing a high mortality rate (23\%), which was much higher than for other indications (i.e., UNOS data (15)). We also identified severe morbidity (Dindo >2) at a rate of $80 \%$. This is likely due to the technically challenging nature of in this setting, with operative difficulties and massive bleeding frequently encountered due to portal hypertension, abdominal adhesions, biliary infection with resistant bacteria, liver abscesses, and previous vascular injuries with cavernous vessels. These factors are likely to contribute to the high rates 
of operative mortality and post-operative complications such as artery thrombosis (5/30) and infections (23/30).

Patients with low MELD scores remained on the waiting list for a long time and were transplanted under sub-optimal conditions, with severe malnutrition due to chronic sepsis or jaundice. Access to LT for such patients is a serious issue. The present study included only patients for whom transplantation was carried out, not those who died while on the waiting list. In the literature, up to $20 \%$ of the patients listed for BDI died while on the waiting list(20,21). Access to grafts is typically straightforward for patients with acute liver failure caused by mixed injuries; however, such cases are rare, and most patients on waiting lists suffer from chronic liver disease and have a median MELD score of 16. Among these patients, the indications included recurrent cholangitis, symptomatic hypertension or refractory pruritus rather than hepatic failure. We highly recommend that patients with iatrogenic disease may benefit from being prioritized for special consideration by national regulatory agencies, so that they can be optimally prepared (e.g., in terms of nutrition and biliary / abscess drainage) and transplanted as soon as possible.

Specific surgical and medical considerations should be made in the management of these patients, such as the use of extracorporeal venous bypass in cases of severe portal hypertension, reduction of post-LT immunosuppression in infected patients, and intensive post-operative renutrition from jejunostomy.

Although the post-operative risks were high, the long-term results of LT were relatively positive, with a five-year survival of rate $70 \%$, showing that LT is the only effective treatment for severe BDI .

In conclusion, LT is the last and only option for severe BDI and for the sequalae of BDI management including secondary biliary cirrhosis or recurrent untreatable cholangitis. These difficult transplantations, which are fortunately rare in France and worldwide, are associated with good long-term results but high morbidity and mortality, as well as a $6.7 \%$ rate of re-transplantation, mainly linked to sepsis and vascular complications. 
To improve upon these short-term results, it is necessary to facilitate access to liver grafts to avoid death on the waiting list and provide patients with LT at an optimal time. Furthermore, LT should be performed by experienced transplant surgeons and anesthesiologists because of the unique operative management requirements for these patients.

The English in this document has been checked by at least two professional editors, both native speakers of English 


\section{REFERENCES}

1. PMSI (French program for the medicalization of information systems). 2017.

2. Li J, Frilling A, Nadalin S, Paul A, Malagò M, Broelsch CE. Management of concomitant hepatic artery injury in patients with iatrogenic major bile duct injury after laparoscopic cholecystectomy. Br J Surg. 2008 Apr 1;95(4):460-5.

3. Buell JF, Cronin DC, Funaki B, Koffron A, Yoshida A, Lo A, et al. Devastating and Fatal Complications Associated With Combined Vascular and Bile Duct Injuries During Cholecystectomy. Arch Surg. 2002 Jun 1;137(6):703-10.

4. Stewart L, Robinson TN, Lee CM, Liu K, Whang K, Way LW. Right hepatic artery injury associated with laparoscopic bile duct injury: incidence, mechanism, and consequences. J Gastrointest Surg Off J Soc Surg Aliment Tract. 2004 Aug;8(5):523-30; discussion 530-531.

5. Winslow ER, Fialkowski EA, Linehan DC, Hawkins WG, Picus DD, Strasberg SM. "Sideways": Resoff tRepauf BiliaryInjuries Using Policyof SideTo-Side HepaticoJejunostomy: Ann Surg. 2009 Mar;249(3):426-34.

6. Arnaud Alves, Olivier Farges, Jacques Belghiti. Incidence and Consequence of an Hepatic Artery Injury in Patients With Postcholecystectomy Bile Duct Strictures. Ann Surg. 2003 Jul;238(1):93-6.

7. Strasberg SM, Hertl M, Soper NJ. An analysis of the problem of biliary injury during laparoscopic cholecystectomy. J Am Coll Surg. 1995 Jan;180(1):101-25.

8. B. N. J. Thomson, R. W. Parks, O. J. Garden. Early specialist repair of biliary injury. BJS. 2006 Feb;93(2):216-20.

9. Schmidt SC, Langrehr JM, Hintze RE, Neuhaus P. Long term results and risk factors influencing outcome of major bile duct injuries following cholecystectomy. Br J Surg. 2005 Jan 1;92(1):76-82.

10. Lubikowski J, Chmurowicz T, Wójcicki M. Liver transplantation as an ultimate step in the management of iatrogenic bile duct injury complicated by secondary biliary cirrhosis. Ann Transplant. 2012;17:38-44.

11. Yan J-Q, Peng C-H, Shen B-Y, Zhou G-W, Yang W-P, Chen Y-J, et al. Liver transplantation as a treatment for complicated bile duct injury. Hepatogastroenterology. 2011 Feb;58(105):8-13.

12. Lauterio A, De Carlis R, Di Sandro S, Ferla F, Buscemi V, De Carlis L. Liver transplantation in the treatment of severe iatrogenic liver injuries. World J Hepatol. 2017 Aug 28;9(24):1022-9.

13. Parrilla P, Robles R, Varo E, Jiménez C, Sánchez-Cabús S, Pareja E, et al. Liver transplantation for bile duct injury after open and laparoscopic cholecystectomy. Br J Surg. 2014 Jan 1;101(2):63-8. 
14. Ardiles V, McCormack L, Quiñonez E, Goldaracena N, Mattera J, Pekolj J, et al. Experience using liver transplantation for the treatment of severe bile duct injuries over 20 years in Argentina: results from a National Survey. HPB. 2011 Aug 1;13(8):544-50.

15. Garcia CR, Acosta LF, Mei X, Berger J, Shah MB, Daily MF, et al. Liver Transplantation for the Treatment of Complicated Iatrogenic Biliary Injuries: A National Review from the UNOS Dataset. Transplantation [Internet]. 2017 Oct 17 [cited 2017 Oct 19];Online First. Available from: http://journals.lww.com/transplantjournal/Abstract/onlinefirst/Liver_Transplantation_for_the_Treatment_of.96838.aspx

16. Savader SJ, Lillemoe KD, Prescott CA, Winick AB, Venbrux AC, Lund GB, et al. Laparoscopic cholecystectomy-related bile duct injuries: a health and financial disaster. Ann Surg. 1997 Mar;225(3):268-73.

17. Hariharan D, Psaltis E, Scholefield JH, Lobo DN. Quality of Life and Medico-Legal Implications Following Iatrogenic Bile Duct Injuries. World J Surg. 2017 Jan;41(1):90-9.

18. Halbert C, Pagkratis S, Yang J, Meng Z, Altieri MS, Parikh P, et al. Beyond the learning curve: incidence of bile duct injuries following laparoscopic cholecystectomy normalize to open in the modern era. Surg Endosc. 2016 Jun;30(6):2239-43.

19. Strasberg SM, Helton WS. An analytical review of vasculobiliary injury in laparoscopic and open cholecystectomy. HPB. 2011 Jan;13(1):1-14.

20. Thomson BNJ, Parks RW, Madhavan KK, Garden OJ. Liver Resection and Transplantation in the Management of Iatrogenic Biliary Injury. World J Surg. 2007 Dec 1;31(12):2363-

9.

21. Santibañes E de, Ardiles V, Gadano A, Palavecino M, Pekolj J, Ciardullo M. Liver Transplantation: The Last Measure in the Treatment of Bile Duct Injuries. World J Surg. 2008 Aug 1;32(8):1714-21.

22. Brunt L, Deziel D, Telm D, Strasberg S, Aggarwal R, Asbun H, et al. Safe Cholecystectomy Multi-society Practice Guideline and State of the Art Consensus Conference on Prevention of Bile Duct Injury During Cholecystectomy. Ann Surg. juill 2020;272(1):3-23.

23. Iannelli A, Paineau J, Hamy A, Schneck A, Schaaf C, Gugenheim J. Primary versus delayed repair for bile duct injuries sustained during cholecystectomy: results of a survey of the Association Française de Chirurgie. HPB. août 201;15(8):611-6. 
Figure 1: Number of liver transplantations for iatrogenic bile duct injury, with corresponding number of bile duct injuries among all liver transplantations in the study period.

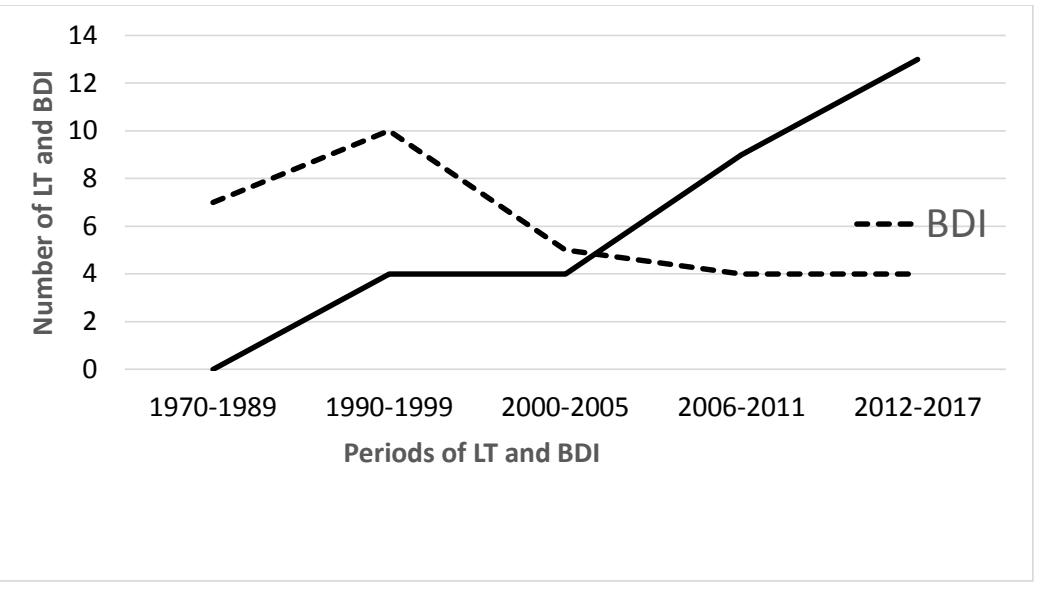


Figure 2: Kaplan-Meier plots of graft and patient survival after liver transplantation for iatrogenic bile duct injury. The survival curves did not significantly differ $(\mathrm{p}=0.586)$.

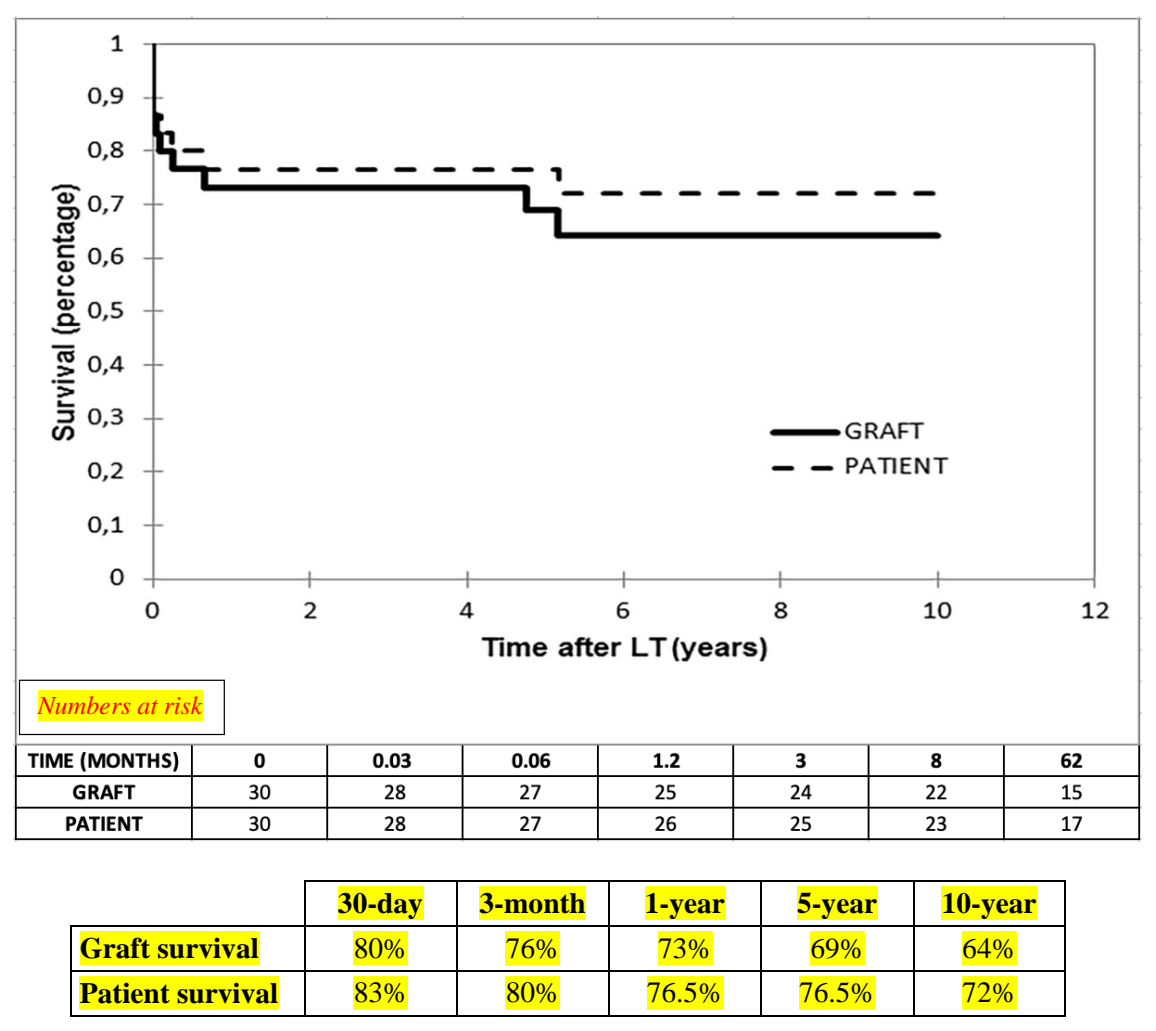


Table 1: Patient demographics and characteristics.

\begin{tabular}{|l|c|}
\hline \multicolumn{1}{|c|}{ Patient characteristics } & All patients $(\mathbf{n}=\mathbf{3 0})$ \\
\hline Sex ratio (M/F) & $11 / 19$ \\
\hline Median age at BDI (years) & $40(9-66)$ \\
\hline Median age at LT (years) & $52(22-68)$ \\
\hline Indication of cholecystectomy & $10(33.3 \%)$ \\
Symptomatic gallbladder & $9(30 \%)$ \\
stones Acute cholecystitis & $1(3.3 \%)$ \\
Common bile duct lithiasis & $2(6.7 \%)$ \\
Biliary pancreatitis & $8(26.7 \%)$ \\
NR & \\
Surgical approach & $20(66.7 \%)$ \\
Laparoscopy & $10(33.3 \%)$ \\
Laparotomy &
\end{tabular}

M: Male; F: Female; BDI: Bile Duct Injury; LT: Liver Transplantation; NR: Not Reported 
Table 2: Diagnosis and type of iatrogenic bile duct injury.

\begin{tabular}{|c|c|}
\hline Diagnosis of BDI & All patients $(n=30)$ \\
\hline \multicolumn{2}{|l|}{ Clinic presentation } \\
\hline Biliary sepsis & $7(23.5 \%)$ \\
\hline Bile leak & $7(23.3 \%)$ \\
\hline Cholestatic jaundice & $5(16.6 \%)$ \\
\hline Upper gastrointestinal & $1(3.3 \%)$ \\
\hline bleeding Secondary biliary & $1(3.3 \%)$ \\
\hline cirrhosis NR & $9(30 \%)$ \\
\hline Median diagnostic delay (days) & $15(0$ - 9855) \\
\hline intra-operative & $4(13.3 \%)$ \\
\hline early post-operative $(<15$ days $)$ & $13(43.4 \%)$ \\
\hline late post-operative (> 15 days) & $9(30 \%)$ \\
\hline NR & $4(13.3 \%)$ \\
\hline \multicolumn{2}{|l|}{ Strasberg classification } \\
\hline $\mathrm{B}$ & $1(3.3 \%)$ \\
\hline $\mathrm{C}$ & $1(3.3 \%)$ \\
\hline $\mathrm{D}$ & $6(20 \%)$ \\
\hline E1 & $3(10 \%)$ \\
\hline E2 & $6(20 \%)$ \\
\hline E3 & $3(10 \%)$ \\
\hline E4 & $5(16.7 \%)$ \\
\hline NR & $5(16.7 \%)$ \\
\hline Associated vascular injury & $11(36.6 \%)$ \\
\hline RHA & $9(81.8 \%)$ \\
\hline CHA & $1(9.1 \%)$ \\
\hline $\mathrm{RHA}+\mathrm{PV}$ & $1(9.1 \%)$ \\
\hline
\end{tabular}

BDI: Bile Duct Injury; NR: Not Reported; RHA: Right Hepatic Artery; CHA: Common Hepatic Artery; PV: Portal Vein 
Table 3: Initial procedures for treatment of iatrogenic bile duct injury.

\begin{tabular}{|c|c|}
\hline Treatment of BDI & All patients $(n=30)$ \\
\hline $\begin{array}{l}\text { Average time between BDI and } \\
\text { initial treatment }\end{array}$ & 24 months \\
\hline $\begin{array}{l}\text { Average number of surgeries per } \\
\text { patient before LT }\end{array}$ & $2.5(1-6)$ \\
\hline Endoscopy/ERCP & $13(43.3 \%)$ \\
\hline Biliary stent & $4(30.8 \%)$ \\
\hline Average number per patient & $1.8(0-4)$ \\
\hline Interventional radiology & $14(46.7 \%)$ \\
\hline Biliary drain & $11(78.6 \%)$ \\
\hline TIPS & $3(21.4 \%)$ \\
\hline Primary hepatico-jejunal anastomosis & $11(36.7 \%)$ \\
\hline Anastomotic stenosis & $9(81.8 \%)$ \\
\hline \multicolumn{2}{|l|}{ Expert center } \\
\hline yes & $10(33.3 \%)$ \\
\hline no & $20(66.7 \%)$ \\
\hline
\end{tabular}

BDI: Bile Duct Injury; ERCP: Endoscopic Retrograde Cholangiopancreatography; LT:

Liver Transplantation; TIPS: Transjugular Intrahepatic Portosystemic Shunt 
Table 4: Liver Transplantation for iatrogenic bile duct injury : general summary.

\begin{tabular}{|c|c|}
\hline Liver Transplantation & All patients $(\mathrm{n}=\mathbf{3 0})$ \\
\hline Median age (years) & $52(22-68)$ \\
\hline Median time BDI / list inscription (years) & $8.5(0.14-32)$ \\
\hline Median duration on waiting list (months) & $3(0.03-45.8)$ \\
\hline Median time BDI / LT (years) & $10(0.2$ - 32) \\
\hline $\begin{array}{l}\text { Associated vascular lesion (years) } \\
\text { No associated vascular lesion (years) }\end{array}$ & $\begin{array}{c}3 \\
11.7\end{array}$ \\
\hline $\begin{array}{c}\text { BDI in an expert center (months) } \\
\text { BDI in a non-expert center } \\
\text { (months) }\end{array}$ & $\begin{array}{r}42.5 \\
144\end{array}$ \\
\hline Median MELD-score & $16(6-40)$ \\
\hline Expert component & $8(26.7 \%)$ \\
\hline Uncontrolled biliary sepsis & $4(13.4 \%)$ \\
\hline Refractory pruritus & $1(3.3 \%)$ \\
\hline Biliovascular destruction & $3(10 \%)$ \\
\hline Median MELD-score & $8(6-18)$ \\
\hline $\begin{array}{l}\text { Median time expert component / LT } \\
\text { (months) }\end{array}$ & $2(0.1-6.5)$ \\
\hline \multicolumn{2}{|l|}{ Indications of LT } \\
\hline Chronic liver failure & $14(46.7 \%)$ \\
\hline Uncontrolled biliary sepsis & $6(20 \%)$ \\
\hline Uncontrolled portal hypertension & $5(16.7 \%)$ \\
\hline Biliovascular destruction & $3(10 \%)$ \\
\hline Acute liver failure & $1(3.3 \%)$ \\
\hline Refractory pruritus & $1(3.3 \%)$ \\
\hline Portal hypertension & $19(63.3 \%)$ \\
\hline
\end{tabular}

BDI: Bile Duct Injury; MELD: Model for End Stage Liver Disease; LT: Liver Transplantation

Table 5: Morbidity and mortality of liver transplantation for iatrogenic bile duct injury. 


\begin{tabular}{|c|c|c|}
\hline Morbi-mortality after LT & All patients $(n=30)$ & Clavien-Dindo \\
\hline Immunologic complications & 8 & \\
\hline Acute rejection & 7 & 2 \\
\hline autoimmune hepatitis & 1 & 2 \\
\hline Vascular complications & 10 & \\
\hline Hepatic artery thrombosis & 5 & $2-3$ \\
\hline Ischemic cholangiopathy & 2 & 2 \\
\hline Pulmonary embolism & 1 & 2 \\
\hline Mesenteric ischemia & 1 & 5 \\
\hline Stenosis of the arterial anastomosis & 1 & 2 \\
\hline Hemorrhagic complications & 9 & \\
\hline Abdominal wall hematoma & 2 & 2 \\
\hline Hemoperitoneum & 2 & 3 \\
\hline Hemorrhagic shock & 3 & $3-5$ \\
\hline Hemothorax & 1 & 3 \\
\hline Cerebral hematoma & 1 & 2 \\
\hline Infectious complications & 23 & \\
\hline Infectious cholangitis & 5 & 2 \\
\hline Septic shock & 4 & 4 \\
\hline Pulmonary infection & 3 & 2 \\
\hline Herpetic stomatitis & 2 & 2 \\
\hline Intra-abdominal abscess & 2 & 3 \\
\hline Peritonitis & 2 & 3 \\
\hline Biliary fistulae & 2 & 3 \\
\hline Acute pyelonephritis & 1 & 2 \\
\hline Acute CMV hepatitis & 1 & 2 \\
\hline Ascites fluid infection & 1 & 2 \\
\hline Parietal complications & 3 & \\
\hline Incisional hernia & 2 & 2 \\
\hline Strangled eventration & 1 & 3 \\
\hline Other complications & 11 & \\
\hline Acute renal failure & 4 & 4 \\
\hline Pneumothorax & 1 & 3 \\
\hline Myoclonic encephalopathy & 2 & 2 \\
\hline Stenosis of the hepatico-jejunal anastomosis & 1 & 3 \\
\hline Bedsore & 1 & 2 \\
\hline Duodenal ulcer & 1 & 2 \\
\hline \multirow[t]{2}{*}{ Portal hypertension } & 1 & 2 \\
\hline & $\begin{array}{c}26 \text { patients } \\
(86.7 \%)\end{array}$ & $\begin{array}{c}24 \text { patients } \geq \text { III } \\
(80 \%)\end{array}$ \\
\hline
\end{tabular}

LT: Liver Transplantation; CMV: cytomegalovirus 


\section{Declaration of interests}

\section{Declaration of interests}

$\bigotimes$ The authors declare that they have no known competing financial interests or personal relationships that could have appeared to influence the work reported in this paper.

$\square$ The authors declare the following financial interests/personal relationships which may be considered as potential competing interests: 


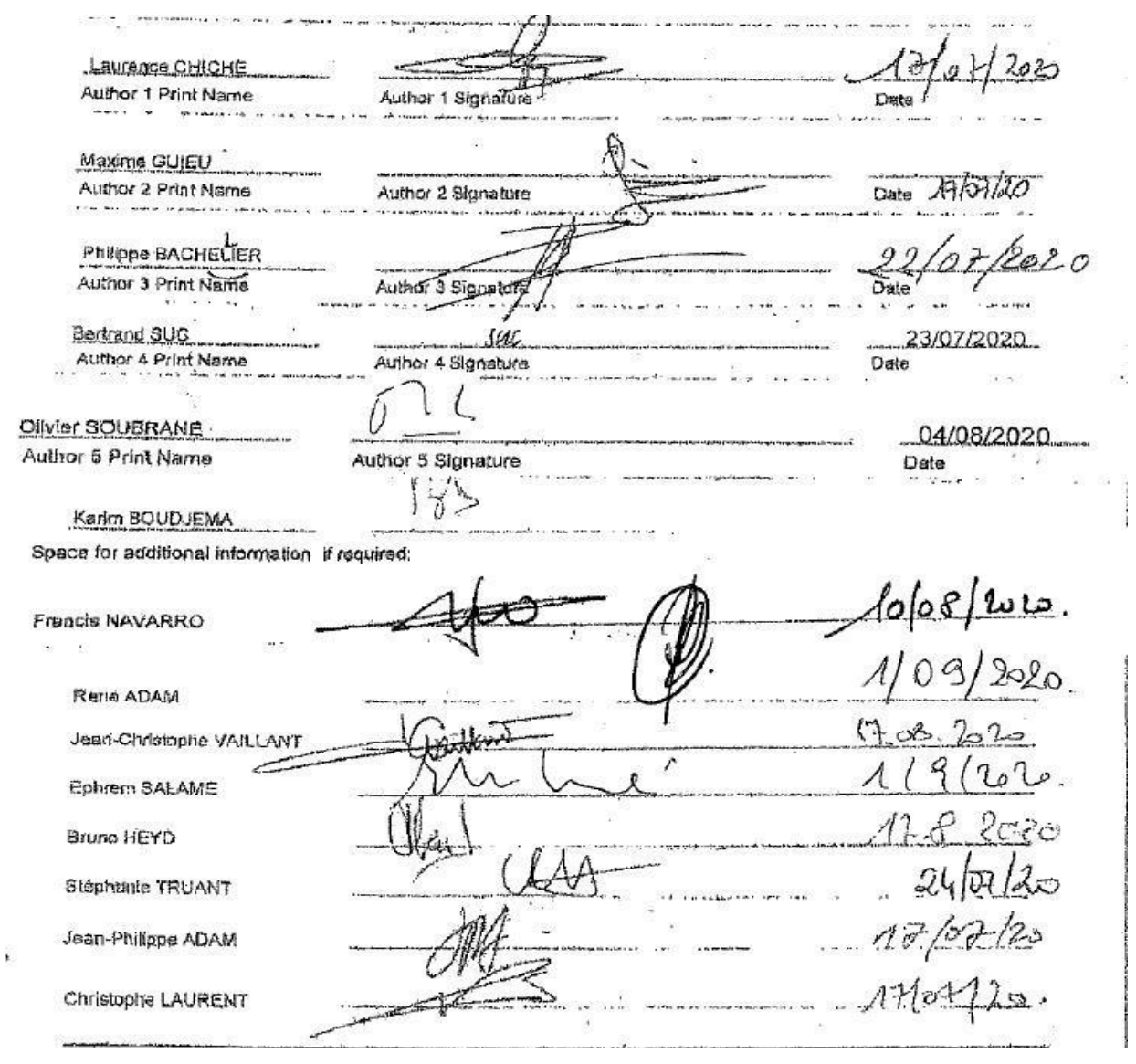




\section{Declaration of interests}

$\bigotimes$ The authors declare that they have no known competing financial interests or personal relationships that could have appeared to influence the work reported in this paper.

$\square$ The authors declare the following financial interests/personal relationships which may be considered as potential competing interests:

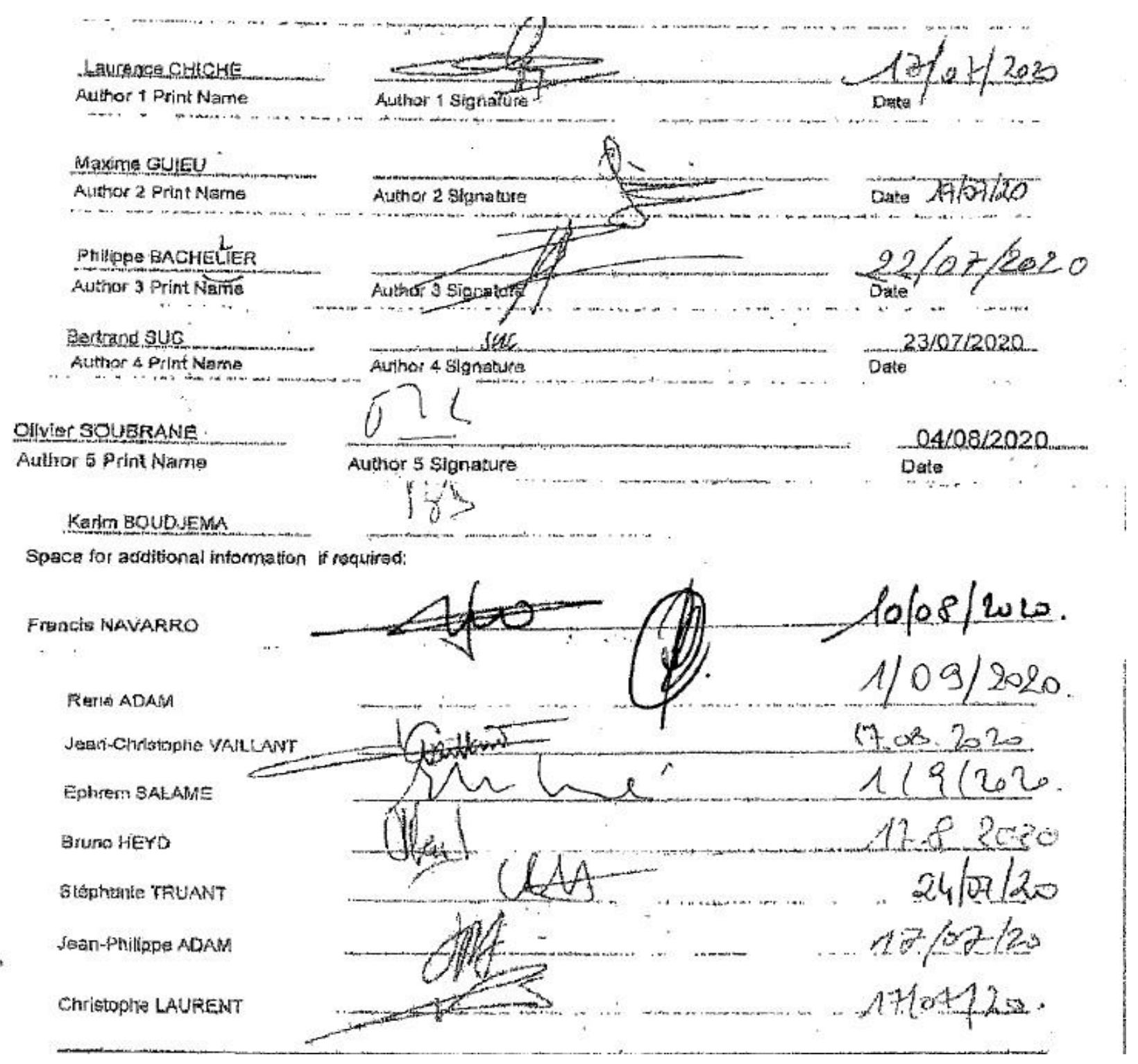

